\title{
A foresight vision for infectious diseases in Africa
}

\begin{abstract}
Author:
Joe Brownlie ${ }^{1}$

Affiliation:

${ }^{1}$ Royal Veterinary College,

United Kingdom, England

Correspondence to:

Joe Brownlie

Email:

jbrownlie@rvc.ac.uk

Postal address:

Royal Veterinary College,

Hawkshead Lane, North

Mymms, Hatfield, Herts, AL9

7TA, United Kingdom

How to cite this proceeding: Brownie, J., 2012, 'A foresight vision for infectious diseases in Africa', Onderstepoort Journal of Veterinary Research 79(2), Art. \#459,

4 pages. http://dx.doi. org/10.4102/ojvr.v79i2.459

Note:

Proceedings of the

Conference of the Southern African Centre for Infectious Disease Surveillance 'One Health' held at the National Institute for Communicable Diseases, Johannesburg, July 2011.
\end{abstract}

(C) 2012. The Authors. Licensee: AOSIS OpenJournals. This work is licensed under the Creative Commons Attribution License.

\section{Introduction}

In 2005, the United Kingdom (UK) through their Foresight programme, within the Government Office for Science (formerly the UK Office for Science and Innovation) launched a project to consider the future risks from infectious diseases for humans, animals and plants (http:// www.bis.gov.uk/foresight/our-work/projects/published-projects/infectious-diseases). Whilst defining these risks, Foresight also explores the very best science that may be brought to transform our ability to manage the future challenges. A Report of the future threats was published in 2006 (Brownlie et al. 2006)

Following the published Report, we highlighted (King et al. 2006) that infectious diseases account for a quarter of all human mortality, and a similar fraction of morbidity (World Health Organisation 2005). Infectious diseases of crops and livestock cost the global economy uncounted billions of euros every year. On top of this, sudden epidemics of infectious diseases can deliver humanitarian and economic shocks on a scale difficult to absorb. According to the World Bank, the 2003 severe acute respiratory syndrome (SARS) epidemic, which killed fewer than 1000 people, was responsible for an estimated 2\% fall in GDP across East Asia; an influenza pandemic could kill millions of people and cost 700 billion euros globally in a single year (European Union 2005). In recent years, there have been numerous outbreaks of livestock and crop diseases costing individual countries billions of euros, for example foot-and-mouth disease (FMD) in Taiwan and the UK; bovine spongiform encephalopathy (BSE) in the UK; Classical swine fever (CSF) in Netherlands; soybean rust in Brazil; southern corn blight in the United States (US); and most recently, avian influenza in Egypt. The UN Millennium Development Goals, as well as having explicit targets for reducing the burden of human diseases (particularly HIV and/or AIDS, tuberculosis and malaria), also have targets for reducing poverty and hunger, but these are compromised by crop and livestock diseases. In most developing regions, where the impacts of infectious disease are greatest, there is now little hope of meeting any of the Millennium Development Goals by 2015 (United Nations 2005).

It was clearly evident that outbreaks of disease can move rapidly and spread across a country, across regions and, in some cases, become global. The best strategy was to stop the disease 'in its tracks' as early as possible. For this to happen, we needed to be able to undertake extremely rapid detection and accurate identification of the pathogens; this would facilitate the correct control measures to be put in place, whether antimicrobials, vaccination or a culling policy. In those early stages, and thereafter, understanding where the outbreak is and its progress through the region is critical for control; thus effective monitoring surveillance and directed epidemiology provides the authorities with key information to target appropriate control measures.

The global nature and threat posed by many diseases is self-evident. For any foresightful look at their potential risk, account must be taken of their global prevalence and impact. With this in mind, the Project enlisted over 300 experts in some 30 countries for consultation and used a variety of methods, including Delphi studies (which use formal methods to generate forecasts from groups of experts), expert reviews, workshops, mathematical modelling and commissioned research.

\section{The emerging and future risks from infectious diseases}

At the conclusion of the final analysis, eight future categories of infectious diseases were identified as high risk and where improved detection systems would make a difference over the next 10-25 years.

- New and emerging diseases, such as SARS and BSE, and novel variants, such as H5N1 subtype influenza A, are anticipated to continue threaten nations.

- Infections becoming resistant to treatment, including antibiotic-resistant bacterial infections, such as tuberculosis and methicillin-resistant Staphylococcus aureus (MRSA) and those where mutation overcomes present vaccine protection, such as influenza. 
- Zoonoses, that is, infections transferring to humans from animals, which can be associated with livestock, pets and, in many cases, with wildlife, for example, SARS, avian influenza, plague, Lyme disease and anthrax. This category includes foodborne infections such as Escherichia coli $\mathrm{O} 157$ or salmonella.

- HIV and/or AIDS, tuberculosis and malaria, the 'Big Three' tropical diseases covered by UN Millennium Development Goal 6.

- Epidemic plant diseases, such as cassava mosaic virus, coffee wilt disease and banana blight, currently of concern in East Africa.

- Acute respiratory infections, a category that covers pandemic influenza and a variety of other viral and bacterial infections.

- Sexually transmitted infections (STIs), including but not only HIV and/or AIDS, which are increasing in incidence in many parts of the world.

- Transboundary Animal diseases, such as FMD, CSF and Newcastle disease, which remain amongst the most important barriers to international trade in livestock and livestock products.

\section{International dimension of foresight and infectious diseases}

It is obvious that global disease needs a global vision. To this end, the Project looked at infectious disease risks not just within the UK but also across sub-Saharan Africa and in China.

In sub-Saharan Africa, it was clear that the importance of infectious disease could not be greater (Rweyemamu, OtimNape \& Serwadda 2006). It carries the heaviest burden of infectious disease of any region; the impact of HIV and/or AIDS, malaria and tuberculosis cannot be over-emphasised whilst the so-called 'neglected diseases' are ever-present and must not be forgotten. The seriousness of plant diseases is quickly seen on whole communities who solely rely on them for their own food and for nutrients for their livestock. The ultimate consequence of crop failure is starvation, rural migration, de-population of whole tracts of agricultural land but, at worse, it is death.

For livestock, the situation in some areas and some times, is not much better. Twelve of the 15 transboundary livestock diseases, formerly considered by the OIE as the most contagious (and which, in many countries, are notifiable to their government), are to be found in Africa. In the UK, they are all exotic. The situation in Africa has worsened in recent years with the further spread of diseases such as contagious bovine pleuropneumonia (CBPP), of Peste des petits ruminants virus (PPRV) and Rift Valley fever virus (RVFV).

This scourge of animal disease cuts deeper where there is poor governance and reduced infrastructure for the livestock extension services and limited diagnostic services. To compound the problem, these highly infectious diseases close all-important regional and global livestock markets that are so valuable to provide income back into the further development of agricultural communities.

The recent advances in technology have promoted rapid penside tests that have the potential to help with the diagnosis of infectious diseases. For sub-Saharan Africa, these tests, to be effective, will need to operate across a number of different countries, diverse systems of culture and governance and be cost effective; the question of global equity then becomes a critical issue.

For those of us involved with the sub-Saharan Africa Foresight project, it became clear that to have any long-term value or sustainability, a new paradigm for an integrated approach to control infectious diseases was needed. This gave rise to the 'pan-African Vision and Strategy for the management of infectious diseases' (Rweyemamu et al. 2006).

The mission statement, at that time, for a pan-African Vision and Strategy for the management of infectious diseases was:

A pan-African concerted effort, shared by AU member governments reflecting the needs of the African society and supported by the international community, with the goal of society protecting from the ravages of dangerous infectious disease that compromise human, and animal and plant health, improved livelihoods, agriculture and economic development.

\section{The birth of Southern African Centre for Infectious Disease Surveillance}

The Foresight 'Detection, Identification and Monitoring of Infectious Diseases (DIM)' Project provided a number of findings which were taken up by a number of governments, agencies and organisations across the world. However, one of the outcomes that was pertinent only to sub-Saharan Africa, was the creation of a Centre for infectious diseases. In time, it was hoped that this would provide the African continent with a capability for diagnosis and identification of any new and emerging diseases; a capability similar to that provided by the Centres for Disease Control and Prevention (CDC) in Atlanta for the USA. Such a Centre would give greater 'ownership of disease' to African countries and thereby promote an African capability that would underpin the national and international control programmes, some of which were of only African interest.

To create such a Centre, we needed to start 'small' (in relative terms, for such an enormous continent), establish a local grouping of countries, find a vision and obtain some start up funds that would be independent of individual Government sponsorship.

The initial project was to join medical and veterinary institutions in Tanzania in a 'smart partnership' with relevant UK institutions (together to focus on human and animal diseases in a virtual Centre incorporating a small but selected number of Institutes, organisations and universities from the 
two countries. The proposal ('Piloting African-UK Partnership through 'One-Medicine' Surveillance and Detection of Infectious Diseases in Tanzania') was submitted for funding to the Wellcome Trust in the UK in 2008 with the Royal Veterinary College (Principal Investigator $=$ Professor Joe Brownlie) as the UK Institution and with the Veterinary School at the University of Sokoine, Tanzania. This proposal failed to obtain funding but did start a series of actions both within the Wellcome Trust and within our Tanzanian collaborators - most notably Professor Mark Rweyemamu. The reasons for failure included the need for African leadership, wider country involvement and better 'take-up' by the medical sciences.

The invitation from the Wellcome Trust to reconsider the proposal required a deeper and more extensive African involvement. At this point, an inspired African leader took the reins and rode the proposal through and over the difficult cross-country obstacle race to win the race and be awarded the invaluable prize of Wellcome Trust funding. That leader was Professor Mark Rweyemamu and the ultimate prize was the creation of the Southern African Centre for Infectious Diseases and Surveillance (SACIDS) with 5 Southern African countries involved (Republic of South Africa, Tanzania, Zambia, Botswana, Mozambique, Democratic Republic of Congo) and a number of Institutions from London, UK (The Royal Veterinary College, the London School of Hygiene and Tropical Medicine and the London International Development Centre). The proposal to Wellcome Trust was entitled SACIDS.

\section{The importance of Southern African Centre for Infectious Disease Surveillance}

The main thrust of SACIDS is create a virtual Centre within Southern African countries with the capacity to provide effective diagnostic capability and research of international standard on infectious diseases, both medical and veterinary, and to provide training to the next generation of young African scientists with the long term ambition to populate the Centre and the relevant Institutions within the Southern African countries. This requires both new graduate courses in the molecular sciences and epidemiology to be designed, approved and initiated in SACIDS member universities and to rapidly incorporate the new technologies that would underpin national diagnosis and surveillance.

Returning to the Foresight programme for a moment (King et al. 2006), we can see that 'a wide range of technological advances from remote sensing to nanotechnology were reviewed and ultimately four were selected for detailed consideration. Novel information technologies for the capture, analysis and modelling of data are already being developed: these will allow data to be collected electronically from hand-held devices, or from remote sensors, and analysed and modelled in real time. Genomics and postgenomics approaches will allow the rapid characterisation of pathogens. Mass screening of people, animals and plants in transit should become feasible through non-invasive detection systems for volatile organic chemicals or atypical electromagnetic profiles. Portable devices will become available for diagnosing infections in individual patients, animals or plants, satisfying a growing demand for cheap, quick, easy-to-use, over-the-counter products, perhaps resembling today's home pregnancy test kits. Some of these technologies will be generic, such as 'lab-on-a-chip' screening for a range of infectious agents, non-specific diagnostics based on detecting activated immune responses, or simple tests to differentiate between viral and bacterial infections to aid the appropriate prescription of antibiotics.

Better disease detection capability is vital but will present challenges as well as opportunities. New technologies must be embedded within functional national or international surveillance systems. In practice, while the widespread use of self-administered tests, for example, could provide valuable data, it is not clear whether or how government agencies would gain access to it. Other kinds of information e.g., records from mobile phones or traffic cameras to follow movements, are potentially valuable for disease control purposes, particularly in outbreak situations, but the public might not accept their use for this purpose. There is always the danger that disease data could be used to discriminate against individuals without providing any benefit or compensation. Similarly, technologies deployed by developed countries could disadvantage developing countries by restricting travel and trade on the basis of the presence or even the suspicion of an infectious disease. Finally, everywhere in the world, better disease data might raise public alarm and expectations of effective action, whether or not this is realistic. This requires that surveillance is operationally linked to an appropriate response. For example, the Global Plan to Stop TB relies on the combination of case detection and directly observed therapy (DOTS) (World Health Organisation 2006) and plans to combat influenza involve surveillance, drug delivery and vaccine production (Fouchier et al. 2005).

Southern African Centre for Infectious Disease Surveillance has the real opportunity to co-ordinate the most important and impressive programme across the Southern African countries to combat infectious diseases in humans and Livestock. It needs to foster interdisciplinary approaches to infectious disease research that transcend both national and also traditional intellectual boundaries, such as those between medicine and veterinary medicine or between virology, bacteriology, mycology and parasitology. A better understanding of patterns of infectious disease also needs input from disciplines as diverse as anthropology, economics and climatology. Quantifying these relationships and understanding their dynamics requires inputs from statistics and mathematics to generate credible models. Health systems research is needed to understand how new technologies can be used most effectively, and must include consideration of the needs, expectations, capabilities and sensitivities of end users and other stakeholders (King et al. 2006).

SACIDS has already done what a couple of years ago would have been considered highly unlikely; with a little more effort over the next few years, it could achieve the impossible - a fully functional SACIDS that has morphed into a continental 
sub-Saharan Centre for Infectious Disease Surveillance and Control.

\section{References}

Brownlie, J., Peckham, C., Waage, J., Woolhouse, M., Lyall, C., Meagher, L. et al., 2006 Foresight. Infectious Diseases: Preparing for the future Future Threats. Office of Science and Innovation, London, p. 1-83.

European Union, 2005, Impact Assessment Avian Influenza, viewed n.d., from http:// archive.defra.gov.uk/
Fouchier, R., Kuiken, T., Rimmelzwaan, G. \& Osterhaus, A., 2005, 'Global task force for influenza', Nature 435, 419-420. http://dx.doi.org/10.1038/435419a, PMid:15917779

King, D.A., Peckham, C., Waage, J.K., Brownlie, J. \& Woolhouse, M., 2006, 'Infectious Diseases - Preparing for the future', Science 303, 1392-1393. http://dx.doi. org/10.1126/science.1129134, PMid:16959992

Rweyemamu, M., Otim-Nape, W. \& Serwadda, D., 2006, Foresight. Infectious Diseases: Preparing for the future, Africa, Office of Science and Innovation, London, $p$ $1-120$.

United Nations, 2005, The Millennium Development Goals Report 2005, UN, New York.

World Health Organization, 2006, Stop TB Strategy to fight the global tuberculosis epidemic, viewed n.d., from http://www.who.int/tb/features_archive/stop_tb_ strategy_launch/en/index.html 